\title{
IS FORESTRY RESEARCH IN CANADA ADEQUATE? ${ }^{1}$
}

\author{
BY V. J. NORDIN ${ }^{2}$
}

\section{HistoricAL}

Although the Administration of the forests is constitutionally a provincial responsibility, research in forestry has been carried out by the Federal Government since the early decades of this century. In general, the provinces and industry have come to regard the Federal Government as the principal forest research agency. In addition, however, the Provinces of British Columbia, Saskatchewan, and Ontario maintain forest research branches and research in forestry and related fields is also conducted by provincial research councils, universities, and agencies such as the Pulp and Paper Research Institute.

The Department of Forestry was established October 1, 1960 and we have therefore just passed the third anniversary of its founding. The initial elements of the Department were the Forestry Branch of the Department of Northern Affairs and National Resources and the Forest Biology Division of the Department of Agriculture.

\section{General Objectives}

In general, the objectives of the Department can be stated as follows:

i. To undertake comprehensive programs of research relating to forestry and the utilization of forest products.

ii. To promote improved management and protection of our forest resources, more effective utilization of wood and reduction in waste, and improvement of the competitive position of our forest industries.

iii. To undertake, promote, and recommend measures for the encouragement of public co-operation in the protection and wise use of forest resources.

The Department, through its Minister, may enter into agreements with the government of any province or with any person for forest protection and management or for forest utilization.

\section{Present Organization}

In organization, the Department presently consists of 4 Branches and one Division: The Administration Branch, Forest Research Branch, Forest Entomology and Pathology Branch, Forest Products Research Branch, and the Economics Division.

We are concerned this morning with forest research and this involves the last four of these units.

\footnotetext{
${ }^{1}$ Contribution No. 1056, Forest Entomology and Pathology Branch, Department of Forestry, Ottawa, Canada.

${ }^{2}$ Assoc. Director, Forest Entomology and Pathology Branch, Dept. of Forestry, Ottawa, Ont.
} 
The Forest Research Branch conducts research in various fields that include silviculture and management, forest fire research, forest inventories, tree breeding, and forest ecology. The Forest Entomology and Pathology Branch undertakes research and surveys of forest diseases and insects and also provides technical advisory services to provincial forestry departments, industrial firms, associations, municipalities, private owners, and others concerned with control of insects and diseases affecting forests, woodlots, and shade trees. The Forest Products Research Branch undertakes research on the development of new and better uses for wood products, on the improvement of manufacturing techniques to obtain more complete and more economic utilization of wood substance, and on the mechanical, anatomical, physical, and chemical properties of Canadian woods. The Economics Division program is designed to keep the economic position of Canada's forest industries under review, to keep informed on international forestry developments throughout the world to assess Canada's competitive position and, more pertinent to our subject of research today, to conduct economic studies relating to forestry in Canada.

\section{THE Future}

This, then brings you up to date and leads into the concluding remarks of this initial statement and to this question. Are we in the Department of Forestry satisfied with our present situation and development? The answer is no! We are not satisfied with our present status and progress. In fact, we are impatient to advance and we are acutely aware of the need for a national forestry agency with a capacity appropriate to meet the needs of forestry in Canada.

But the picture is definitely optimistic. We must keep in mind that the Department is only three years old and that changes and advance cannot be effected "overnight". Progress is being made, worthwhile and encouraging progress, within the scope of our present budget, organization, and available personnel. We are under no illusions, however, that we have done anything but barely scratch the surface in fulfilling desired aims and objectives.

We have a long way to go before the Department will reach a stage of development commensurate with the dimension of the needs for improved forest research. As a Department we are not satisfied that we are providing adequately in some areas of research needed by industry and provincial governments. We aim to develop and shape vigorous programs realistically with new directions and emphasis to meet continuing and rapidly changing circumstances which characterize this fast moving age of machines and computors.

As one example of our wish to find out more about how we can best be of service, for the first time in the history of Canada, the Minister of Forestry will convene a significant meeting this October 21-22 with the Forest Ministers of the 10 Provinces and their senior advisors. This meeting will be significant to Departmental planning and positive action.

To conclude, gentlemen, it is quite clear that without comprehensive programs of forest research, Canada would ultimately fail in her obligation to provide optimum management of her forest resources and to continue to compete successfully on the world markets. 
I might also do some "regeneration" of thoughts that our Deputyminister, Dr. L. Z. Rousseau, has already planted; that we are a lookahead Department and we are optimistic that we will advance in forest research with the excellent co-operation of the forest agencies throughout Canada that we now enjoy. And let there be no question that our goal in the Department of Forestry, with the encouragement and constructive support of all forestry agencies, is to vigorously undertake our responsibilities to the maximum benefit of the Canadian forestry community.

On What Basis Does The Department Of Forestry Allocate Funds And

Research Manpower To The Different Regions Of Canada And To Various Fields OF Research? Is It Reasonable?

This question has a number of parts and each of these can be examined from several points of rview.

First, how does the Department of Forestry allocate funds and research manpower to the different forest regions of Canada and the various fields of research? In general, our available funds and manpower are determined and allocated by need. In other words, the research service to the forestry community will vary in emphasis from region to region and is largely determined:

1. By differences in the importance of forestry to the economy in different regions.

2. By the scale and diversity of Canadian Forestry as reflected by differences in forest sites, topography, and climate.

3. By differences in the relative sophistication and scope of management, utilization, and manufacturing procedures.

4. By differences in the adequacy of provincial governments, universities, and other research services that are available to complement Department of Forestry programs.

A second part to this question states, "is it reasonable?"

If this question refers to the general principles of allocating resources to regions we would say yes.

However, there is a present imbalance in the current allocation of funds within our Department in the distribution of $50 \%$ of operational funds to forest disease and insect research, $15 \%$ to forest products research, and $35 \%$ to all other forest research activities.

This distribution is not by design but developed before the formation of the new Department when the two major elements, the Forestry Branch and the Forest Biology Division, were brought together each originating from different Departments and each entering the new Department of Forestry with established programs, personnel, and funds. This is an imbalance of which the Department is acutely aware and is vigorously striving to improve.

Again, if the question "is it reasonable" refers to the present total allocation of funds to Forestry Research, the answer is a large NO!

This inadequacy of funds for the total forestry research effort is obvious in many ways. This inadequacy, for example, can be indicated by comparing the moneys currently expended for research by other federal Departments. In relation to the net value of products, each of three other 
federal government departments undertaking programs of research spends annually at least $50 \%$ more on research than is currently expended by the Department of Forestry, yet the value of forest products far exceeds or compares favourably with the value of products represented by these three Departments.

I might also add briefly at this point that the present organization may not facilitate maximum co-ordination of resources and examinations of research on a problem basis and I can only say at this time that such departmental considerations are presently under intensive scrutiny.

\section{Should The Department Of Forestry Put A Greater Part Of Its \\ Research Into ApPlied Research Where The Results Will Have More ImMEdiate Application IN Solving Forest Management And Protection Problems OF Operating Organizations?}

I should make it quite clear that the Department of Forestry is an organization devoted essentially to applied research in the sense that all research is directly related to solving forestry problems. This is sensible because a primary objective of our Department is to provide service to the Canadian forestry community through research.

In conducting applied research, however, our activities may vary from the most basic to the most practical and developmental. Our basic background research may consider the distribution pattern of photosynthates, the identity of bark substances in relation to disease and insect control, and the genetics of the spruce budworm, but all these are pointing the way to new knowledge that is essential to real progress in practical application; for example, in the application of silvicultural methods to management procedures, in the control of forest diseases and insects, in developing improved methods in fire control, better tree varieties, etc. Such basic background research is an essential part of any healthy and effective program of applied research. In other words, we must ensure a balanced program of research but this balance may vary between regions depending upon many variables such as the scale and diversity of forestry activities and problems and on differences in the scope and sophistication of forestry procedures. In any forest region, therefore, a balanced program can only mean that combination of research that will most likely result in providing the needed services to the forest industries.

Certainly, we have not reached this optimum balance in many areas. For example, our present fire research program is almost exclusively of short term application nature but we feel an urgent necessity to balance this program with additional studies of a basic nature because without such fundamental investigations real progress beyond the frontiers of present knowledge will not be possible and we will be limited in what can be done in practical development. It is interesting that one of the severest criticisms of the Department of Forestry by the Royal Commission on Government Organization was the lack of basic research in important areas of forest and forest products research.

Conversely, in several areas, it is true that the balance may be reversed and that we are not doing enough in the application or developmental fields. 
But for the purposes of this discussion I believe the important points to remember are these:

First, we are in the business of applied research.

Second, we must recognize that from basic background science to practical application we must have a continuum of knowledge. Within our responsibility of applied research, therefore, the research undertaken is directly related to forestry objectives but this research in order to effectively solve problems may vary from the most theoretical to the most practical. But depending upon circumstances already mentioned, it is important that appropriate balances of research be established.

\section{Is The Department Of Forestry Making The Results Of Its} Research Available In The Most Suitable Manner?

First, gentlemen, considering the dissemination of the results of research, the forest scientist has too long neglected to inform the general public of his activities, of his difficulties, and of the impact of his researches on the immediate and long term welfare of the community he serves. We believe that the Department of Forestry has an important responsibility here to adequately keep before the public, the existence and nature of our research to ensure and deserve public support.

In another aspect of our communications in relation to research we need and plan also to place increased emphasis on creating in the public eye a clearly defined image of the Department of Forestry; its work, its policies, and its personnel.

We believe that the Department of Forestry is suitably recording the results of its researches in appropriate scientific journals and in many areas of forest research the record verifies that several Departmental personnel are world leaders in their fields. Further, the Department distributes this information widely in Canada and throughout the world through reprints of these contributions.

However, one of the most urgent objectives that exists within the Department of Forestry is to elaborate on the vital link that must exist between research and profitable forest management and utilization. In other words, are we seeing to it that the results of research reach those who need it in the form they can use it?

The concluding step in research is certainly the publication of the results. But our responsibility does not end here. We need to ensure that these results are interpreted and presented in terms that can be utilized by the woods manager, the practising forester, and the public. As an example, emphasis in this direction is provided in forest products where research results are interpreted in a variety of technical and trade journals. We clearly recognize, however, that we have a big job ahead of us in bridging the large gap that exists between the scientific paper and practical application not only for current and future researches but for a vast fund of scientific data that are already available.

There are other ways to communicate and bridge the research-application gap. The recent establishment of industrial liaison officers to better appreciate the needs of industry and to convey the benefits of research knowledge first 
hand is proving most useful in the area of forest products and increased attention here is receiving careful examination for other Departmental responsibilities.

There are other ways to convey the fruits of research, for example, through short courses on the latest techniques in sawmilling, seasoning, log quality evaluation, and nursery and planting methods. Pilot trials and practical demonstrations to show the value of good management and insect, disease, and fire control are all useful activities and have their place in effectively communicating the results of research.

These are a few examples to indicate that the Department of Forestry is fully aware of the need to expand and improve its activities in conveying the fruits of research in a variety of forms useful to the public and practising foresters.

\section{SUMMARY REMARKS}

The most important and significant impediment to the advance of research in forestry by our Department is the lack of sufficient numbers of qualified and competent professional officers for research along with the required technical personnel and supporting services. Whole areas in specific fields of forestry are receiving no research attention whatsoever and other problems receive inadequate examination simply because we do not have appropriate resources.

Imagine, gentlemen, we have just 11 officers for the whole of Canada to undertake fire research where we now can only examine less than $1 / 3$ of the most urgent problems; imagine, gentlemen, that to meet the immediate urgent requirements for research in fire, mensuration, photogrammetry and surveys, ecology, genetics, soils and site, forest geography, silvics, and wildlife, an additional 160 competent research men could receive immediate assignment. This acute lack of manpower resources permeates our new Department and regretfully we just do not have time today to be specific about the impressive needs in the fields of forest economics and forest products. And other elements in our Department such as forest disease and insect research cannot be neglected because we must sustain, improve, and continue to advance in such areas where we have established effective programs as well as national and international recognition and reputation. We must improve on our weaknesses but not at the expense of impeding progress in activities in which we are currently strong.

In terms of function our greatest single problem undoubtedly is the effective communication of research results in the language of the forest manager. At the same time, however, is it possible that we as foresters need to improve our habits in keeping up to date on forestry literature?

To all of you here today who represent the forest agencies of government and industry throughout Canada, it is a pleasure to acknowledge your very excellent co-operation in the Departmental program of surveys and research. But let us also have your support by effectively communicating your problems to us.

Do this, and given the necessary resources, there is no doubt that we can and will do the job in forestry research that is required by the Canadian forestry community. 